\title{
Tensile Bond Between Substrate Concrete and Normal Repairing Mortar under Freeze-Thaw Cycles
}

\author{
Ye Qian \\ Division of Engineering and Policy for Sustainable Environment, Hokkaido University \\ Department of Civil Engineering and Engineering Mechanics, Columbia University \\ Dawei Zhang \\ College of Civil and Engineering and Architecture, Zhejiang University \\ Tamon Ueda* \\ Division of Engineering and Policy for Sustainable Environment, Hokkaido University
}

\begin{abstract}
Concrete patch repair has long been used to repair the damaged concrete structures. In cold regions, freezethaw cycle is one of the major damage factors. Not only the material itself is damaged by freeze-thaw cycles, but also the adhesive interface, which is regarded as the weakest part of composite system, degrades under freeze-thaw cycles. Air entraining agent has long been used to increase the freeze-thaw resistance of concrete materials. However, the effect of air entraining agent on the adhesive interface under freeze-thaw cycles has not been explored. The degradation mechanism and failure mode of concrete repair system have not been studied, either. In this study, to investigate the effects of water-cement ratio of substrate concrete and air entraining agent in substrate concrete and repairing mortars, three kinds of substrate concrete were casted and repaired by two kinds of ordinary Portland cement mortar. With certain number of freeze-thaw cycles up to 150 cycles, through splitting prism test, the splitting tensile strength and failure mode of composite specimens were experimented. The relative dynamic elastic modulus and splitting tensile strength of substrate concretes and repairing mortars were obtained as well. Results showed that air entraining agent in the repairing mortar greatly influenced the adhesive tensile strength under freeze-thaw cycles. The water-cement ratio and air entraining agent of substrate concrete insignificantly affected the adhesive interface, but affected the splitting tensile strength and the freezethaw resistance of substrate concrete, and thus affected the failure mode of composite specimens.
\end{abstract}

\section{INTRODUCTION}

As existing concrete structures like pavements, bridge decks, dams, etc., aging and degrading, the maintenance and rehabilitation of concrete structures have been a worldwide concern. Concrete patch repair is one of the common repairing methods in which damaged concrete is replaced, the surface is roughened, and newly cast repairing materials are placed on the treated surface of old concrete. It has been noticed by many researchers that the bonding between old concrete and new repairing material is a major issue as in most cases it is the weakest part of the repair system. According to Emmons and Vaysburd (1993) and Morgan (1996), the compatibility between old substrate concrete and new repairing material is a critical issue to obtain a good bonding. Austin, Robins, and Pan $(1995,1999)$ conducted extensive tests on concrete repairs considering the effects of material properties, surface conditions, geometry, loading, and material modulus mismatch. Considering the importance of the interfacial zone in bonding, Li, Xie, and Xiong (2001) studied the bonding by observing the microstructures of interfacial zone of new-to-old concrete system. Because of close mechanical properties and thus good compatibility to substrate concrete and low cost (Morgan, 1996), ordinary Portland cement mortar has been largely used as repairing material.

From the perspective of contractor, Emmons and Vaysburd (1994) pointed out that long-term durability of concrete repair is more important than shortterm bonding strength of newly cast concrete repair. Freeze-thaw cycle is one of the major factors affecting the durability of the bonding of concrete repair system. It causes scaling and cracking in concrete structures. Both using splitting prism test, Li, Geissert, Frantz, and Stephens (1999) and Li, Wang, and Zhao (2007) have presented the degradation of splitting tensile strength of concrete repair system with increasing number of freeze-thaw cycles, taking the surface roughness, surface moisture, and curing condition into consideration. However, as an important component 
of the concrete repair system, the interfacial zone of concrete repair system has not been specifically studied or analyzed. The failure mode of repair system under freeze-thaw cycles has not been clearly explained neither.

In this study, factors affecting the interfacial tensile bond of concrete repair system, such as water-cement ratio in substrate concrete, air entraining agent in repairing mortar, and substrate concrete, were tested and analyzed. The failure mode and degradation of composite specimens under freeze-thaw cycles were presented. The explanation based on microstructural phenomena was introduced for the splitting prism test results including failure mode, splitting tensile strength degradation, and effects of given factors.

\section{EXPERIMENTAL PROCEDURES}

\subsection{Compositions of substrate concrete and repairing mortar}

Three kinds of substrate concrete were casted. The water-cement ratio of normal concrete without and with air entraining agent (marked as N and NA, respectively) is 0.55 , while that of high strength concrete (marked as $\mathrm{H}$ ) is 0.32 . NA and $\mathrm{H}$ were air-entrained with the fresh air content of $5 \%$. The repairing material was ordinary Portland cement mortar (marked as MA containing air entraining agent and $M X$ not containing air entraining agent) with water-cement ratio of 0.50 , where the ratio of cement to sand was $1: 3$ by volume. The fresh air content of air-entrained mortar (MA) was $4 \%$.

\subsection{Preparation of substrate concrete and composite specimens}

Concrete prisms with the dimension of $50 \mathrm{~mm} \times$ $100 \mathrm{~mm} \times 100 \mathrm{~mm}$ were casted. One day later, the concrete prisms were demolded and cured in water tank at a temperature of $20 \pm 1^{\circ} \mathrm{C}$ for 28 days. Then, the surface of the concrete prism to be repaired was sandblasted until the coarse aggregate appeared.

During concrete repairing, the substrate concrete was put into the bottom of the steel mold with the dimension of $100 \mathrm{~mm} \times 100 \mathrm{~mm} \times 100 \mathrm{~mm}$, with the repairing surface toward up. The repairing material was casted on top of the substrate concrete in the mold and compacted using a vibrator. Air-entrained mortar (MA) was casted just after the substrate concrete was sandblasted (1 month curing time for substrate concrete before repairing), whereas non-air-entrained mortar (MX) was casted 8 months later (9 months curing time for substrate concrete before repairing).

Two days after casting, composite prisms with the dimension of $100 \mathrm{~mm} \times 100 \mathrm{~mm} \times 100 \mathrm{~mm}$, as shown in Figure 1, were demolded and cured in water tank for 28 days before being subjected to freeze-thaw cycles.

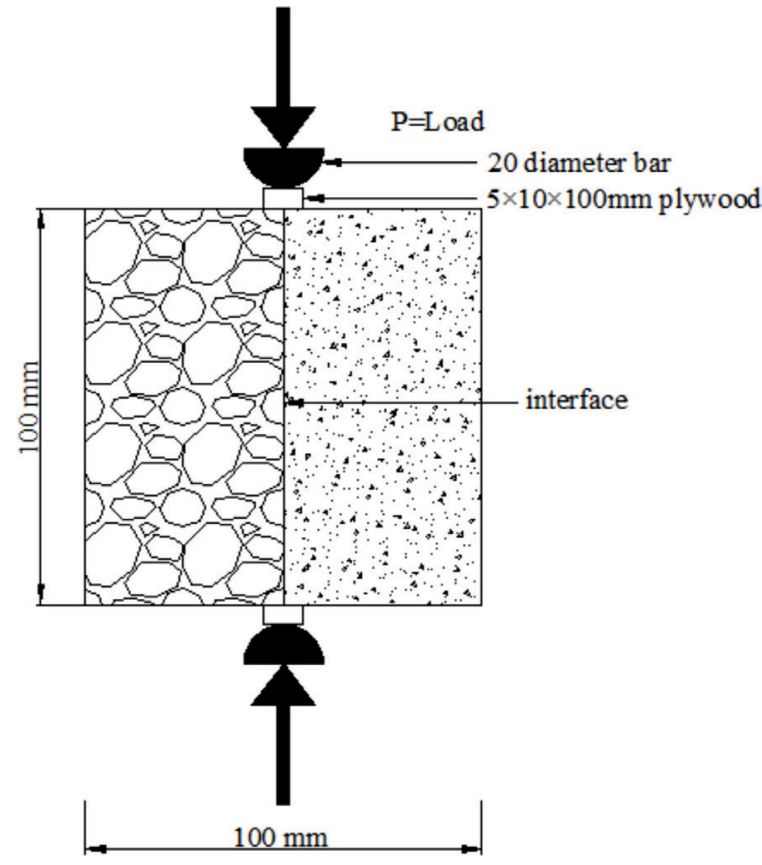

Figure 1. The composite specimen and set-up of splitting prism test.

\subsection{Freeze-thaw cycle experiments}

After water curing for 28 days, composite specimens were put into the environmental chamber to start freeze-thaw cycles. The temperature cycle of the center of the composite specimen accords to ASTM C 66603 procedure A (ASTM C666, 2008). The temperature was set to drop from $4^{\circ} \mathrm{C}$ to $-18^{\circ} \mathrm{C}$ for $1.5 \mathrm{~h}$, kept at $-18^{\circ} \mathrm{C}$ for $0.5 \mathrm{~h}$, rise from -18 to $4^{\circ} \mathrm{C}$ for another $1.5 \mathrm{~h}$, and kept at $4^{\circ} \mathrm{C}$ for $0.5 \mathrm{~h}$. The tested temperature of the center of specimens by thermocouples was close to the set temperature as shown in Figure 2.

\subsection{Relative dynamic elastic modulus test}

During freeze-thaw damage, micro cracks are initiated and propagated, making the elastic modulus of cement, and concrete decreases. Relative dynamic elastic modulus (RDEM) is used to quantify the extent of damage of cementitious material under freeze-thaw damage (ASTM C666, 2008). After certain numbers of

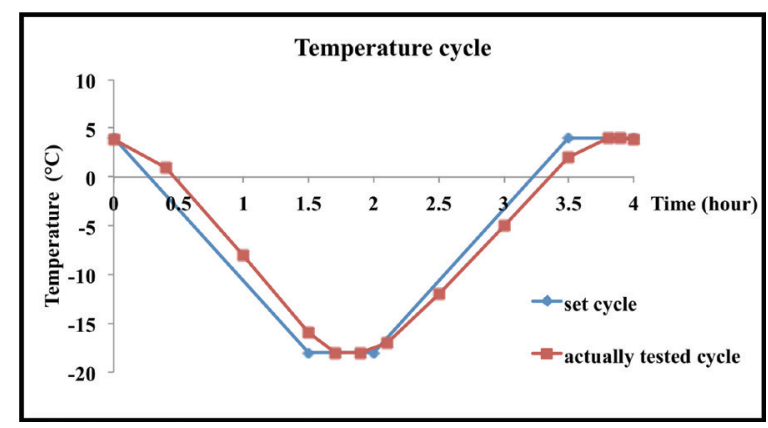

Figure 2. Temperature cycle of the center of specimens. 
freeze-thaw cycles, the $100 \mathrm{~mm} \times 100 \mathrm{~mm} \times 400 \mathrm{~mm}$ concrete prisms were taken out of the chamber to conduct RDEM test. The fundamental transverse frequency of concrete prism was recorded. According to ASTM E 187609 (ASTM E1876, 2009), RDEM is proportional to the square of the ratio of fundamental transverse frequency of $n$ cycles to 0 cycle, as presented in Equation (1).

$$
\mathrm{RDEM}=\left(\frac{F n}{F 0}\right)^{2}
$$

where $F_{\mathrm{n}}$ and $F_{0}$ is fundamental transverse frequency after $n$ cycles and 0 cycle of freezing and thawing, respectively.

\subsection{Splitting prism test}

Geissert (1999) proposed a simple test method to measure the bond strength of composites. The area of substrate concrete-repairing mortar interface is $100 \mathrm{~mm} \times 100 \mathrm{~mm}$. Assuming a uniform tensile stress across the bond plane, the splitting tensile strength is defined and calculated according to Equation (2) (Nilsson, 1961).

$$
f_{\mathrm{t}}=\frac{2 P}{\pi A}
$$

where $f_{t}$ is the splitting tensile strength, $P$ is the maximum applied load, and $A$ is the area of the interface.

\section{EXPERIMENT RESULTS}

\subsection{RDEM of substrate concrete and repairing mortar}

The RDEM of air-entrained material (NA, $\mathrm{H}$, and MA) had nearly no decrease under freeze-thaw cycles, whereas that of non-air-entrained material ( $N$ and $M X)$ decreased obviously, as shown in Figure 3. After 150 freeze-thaw cycles, the RDEM of $\mathrm{NA}, \mathrm{H}$, and MA were 99,100 , and $99 \%$ of the value of 0 cycle, respectively. The RDEM of $\mathrm{N}$ and MX decreased to 63 and $72 \%$ after 150 freeze-thaw cycles.

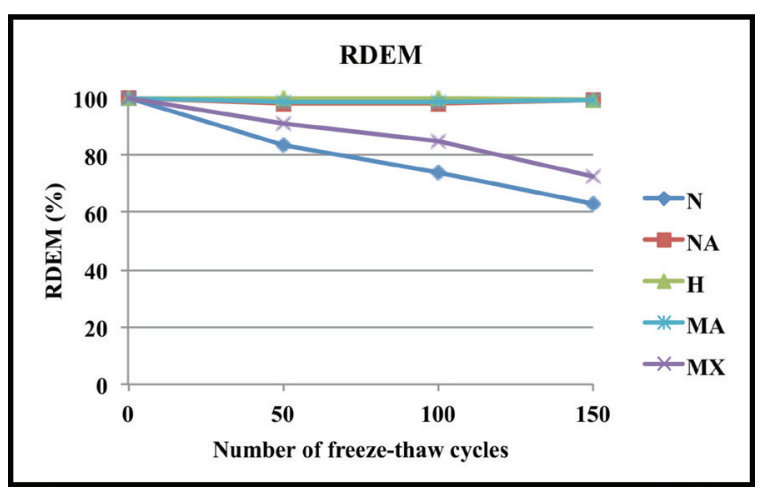

Figure 3. RDEM of substrate concrete and repairing mortar.

\subsection{Splitting tensile strength of substrate concrete and repairing mortar}

Splitting prism tests on substrate concrete and repairing mortar were also conducted to obtain the splitting tensile strength of each constitutive material. Figure 4(a) and (b) show the results of materials used in composites repaired with $M A$ and $M X$, respectively. All the materials with air-entraining agent (NA, $\mathrm{H}$, and MA), showed good frost resistance, whereas the materials without ( $N$ and $M X)$ did not. The splitting tensile strength of $\mathrm{N}$ in composites repaired with MA decreased to $59.6 \%$ after 150 freeze-thaw cycles. The splitting tensile strength of non-air-entrained material ( $N$ and $M X)$ in composites repaired with $\mathrm{MX}$ decreased to 46.6 and $77.6 \%$ after 150 freeze-thaw cycles.

\subsection{Splitting prism test of composite specimens}

\subsubsection{Splitting tensile strength and failure mode of substrate concrete repaired with air-entrained mortar}

For all the splitting prism tests except N-MA composite specimen with 150 cycles, the failure mode was adhesion failure, as shown in Figure 5(a). The

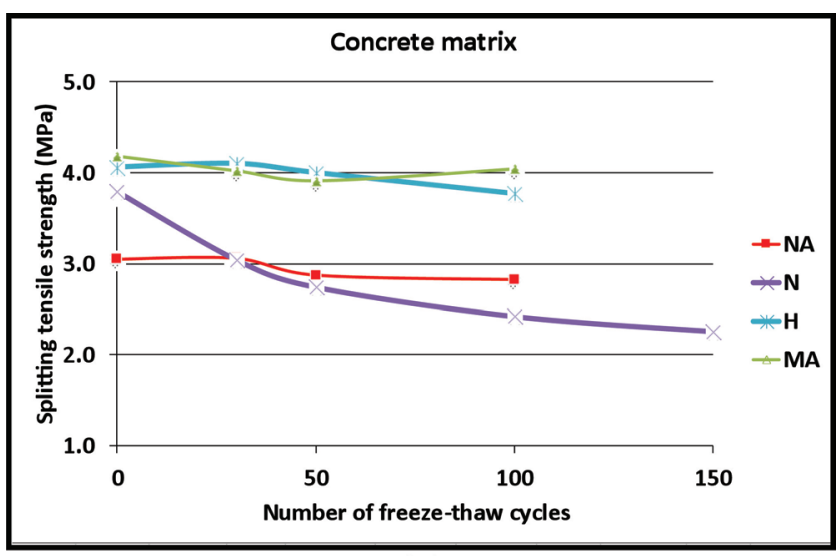

(a)

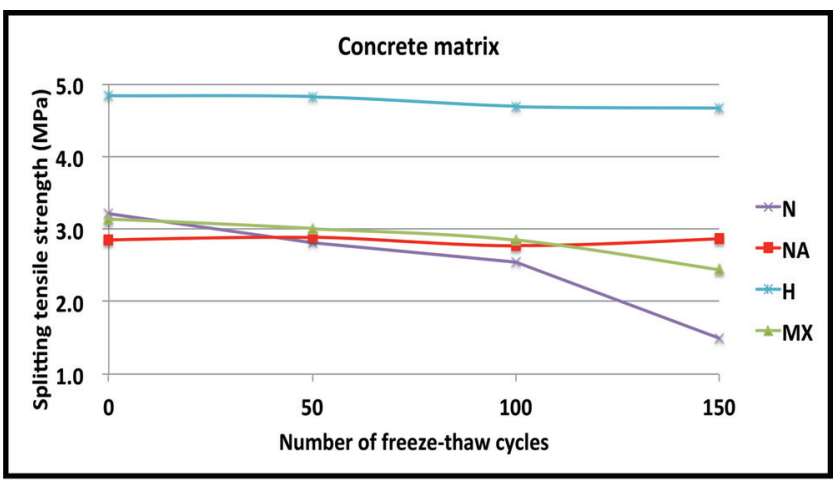

(b)

Figure 4. Splitting tensile strength of substrate concrete and repairing mortar in composites: (a) repaired with MA and (b) repaired with $M X$. 


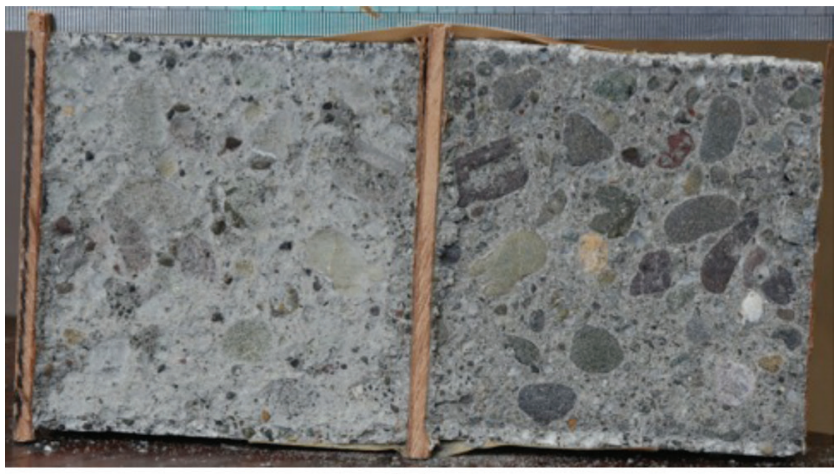

(a)

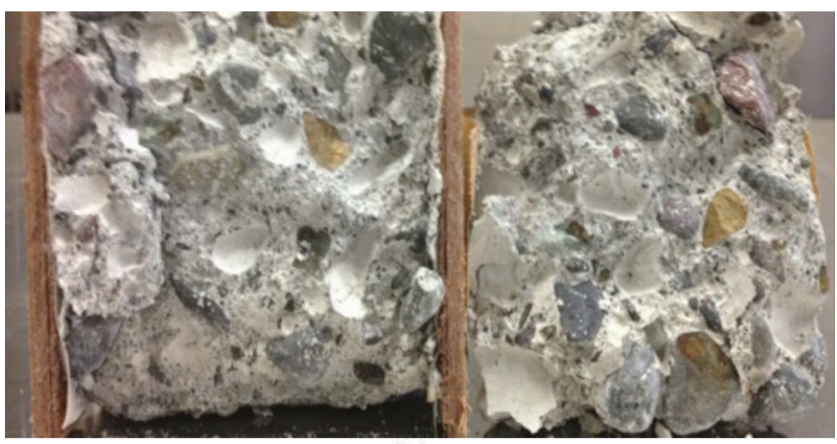

(b)

Figure 5. A typical example of fracture surface of composite specimens: (a) adhesion failure between substrate concrete and repairing material; (b) cohesion failure at $\mathrm{N}$ side.

substrate concrete was distinctly separated from the repairing mortar. For N-MA composite specimen with 150 cycles, the failure mode was cohesion failure in which the fracture happened at normal concrete $(\mathrm{N})$ side, as shown in Figure 5(b).

Results of splitting prism test for composite specimens are shown in Figure 6. The splitting tensile strength of all three kinds of composite specimens did not change obviously under increasing number of freezethaw cycles. Under 150 freeze-thaw cycles, the splitting tensile strength of $\mathrm{N}-\mathrm{MA}, \mathrm{NA}-\mathrm{MA}$, and $\mathrm{H}-\mathrm{MA}$ composite specimens was $100.6,99.7$, and $95.9 \%$ of the value of 0 cycle, respectively.

For NA-MA and H-MA composite specimens, from Figures 6(a) and (b), the splitting tensile strength of composite specimens were always smaller than that of either substrate concrete or repairing mortar without and with freeze-thaw cycles. As the failure mode was adhesion failure, the splitting tensile strength of composite specimen was regarded as splitting tensile strength of adhesive interface. The adhesive interface bonding was the weakest part of the composite specimens with and without freeze-thaw cycles but did not degrade with increasing number of freezethaw cycles.

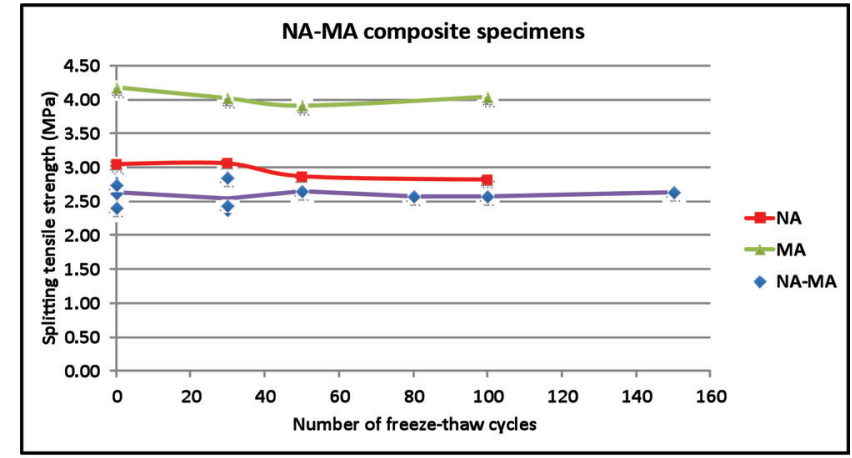

(a)

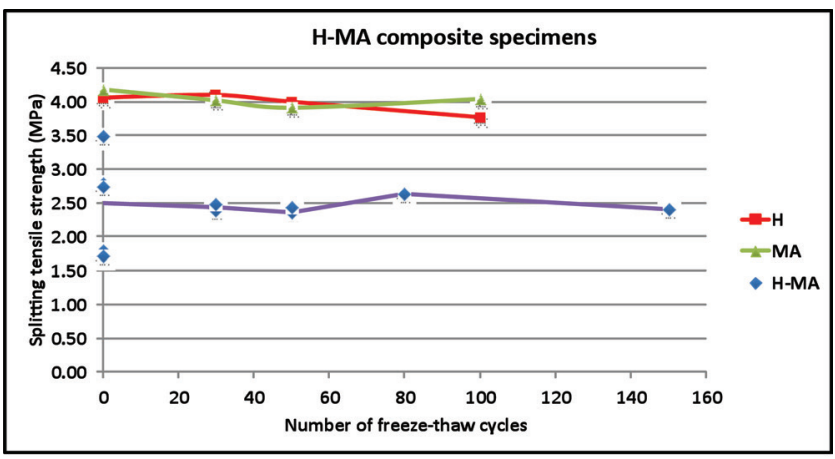

(b)

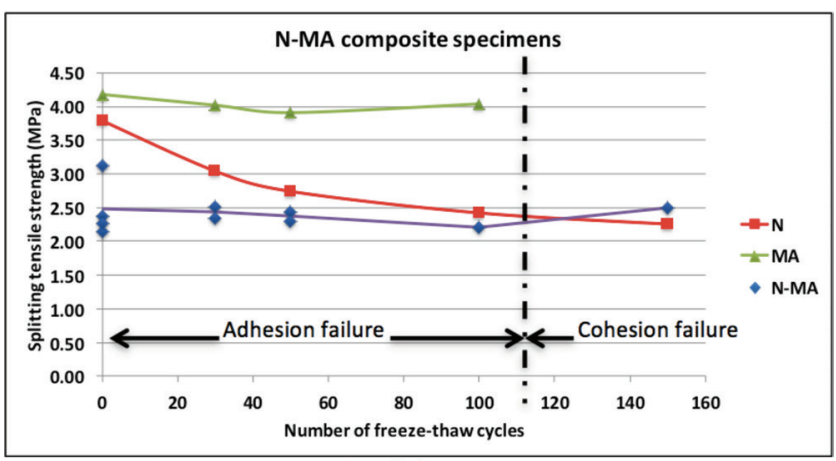

(c)

Figure 6. Splitting tensile strength of composite specimens: NA-MA; (b) H-MA; (c) N-MA composite specimen.

For N-MA composite specimens, until 100 freezethaw cycles, the failure mode was adhesion failure. From Figure 6(c), the splitting tensile strength of composite specimens was smaller than that of either substrate concrete or repairing mortar. However, with 150 freeze-thaw cycles, the splitting tensile strength of normal concrete $(\mathrm{N})$ had decreased to $59.6 \%$ of the value of 0 cycle, and RDEM had decreased to $63 \%$ of the value of 0 cycle, while the splitting tensile strength of the adhesive bonding did not decrease. The splitting tensile strength of normal concrete $(\mathrm{N})$ became smaller than that of adhesive interface or repairing mortar (MA). The failure mode thus shifted from adhesion failure to cohesion failure happened 
at substrate concrete $(\mathrm{N})$ side, showing the substrate concrete $(\mathrm{N})$ became the weakest part of the repair system.

\subsubsection{Splitting tensile strength and failure mode of substrate concrete repaired with non-air-entrained mortar}

Many composite specimens showed mixed failure mode. Figure 7 shows the fracture surface of NA-MX composite specimen after 100 freeze-thaw cycles. In $70 \%$ of the surface, the fracture occurred at the adhesive interface, and the repairing mortar was clearly separated from substrate concrete, while, in the other $30 \%$ of the surface (surrounded by the lines in Figure 7), the repairing mortar bulk fractured. Table 1 shows the splitting tensile strength of composites and the percentage of area for each failure type in all composite specimens repaired with non-air-entrained mortar (MX).

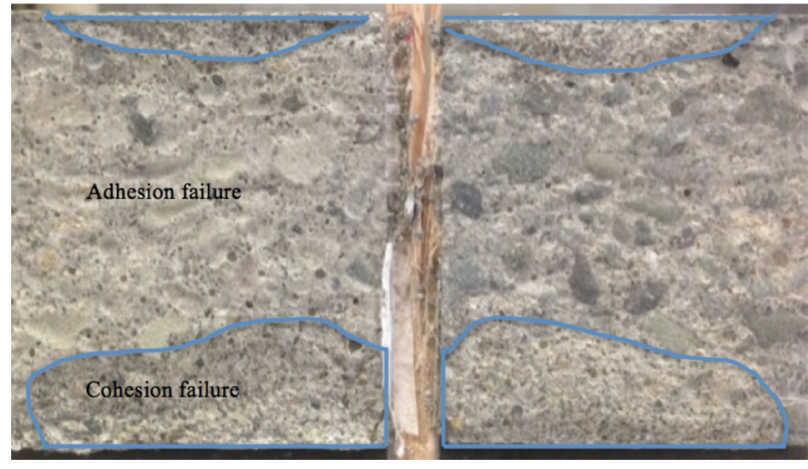

Figure 7. Fracture surface of NA-MX composite specimen after 100 freeze-thaw cycles: $70 \%$ adhesion failure and $30 \%$ substrate failure at the repairing mortar side.

With increasing number of freeze-thaw cycles, the splitting tensile strength of composite specimens repaired with non-air-entrained mortar (MX)

Table 1. Splitting tensile strength of composite specimens repaired with non-air-entrained mortar (MX).

\begin{tabular}{|c|c|c|c|c|c|c|}
\hline \multirow[t]{2}{*}{ Number of cycle } & \multicolumn{3}{|c|}{ NA-MX } & \multicolumn{3}{|c|}{ Failure mode (\%) } \\
\hline & Strength (MPa) & Mean value (MPa) & Degradation (\%) & Substrate & Interface & Repair \\
\hline \multirow[t]{2}{*}{0} & 2.23 & 2.21 & 100 & 20 & 80 & 0 \\
\hline & 2.20 & & & 15 & 85 & 0 \\
\hline \multirow[t]{2}{*}{50} & 1.90 & 2.11 & 95.5 & 5 & 95 & 0 \\
\hline & 2.32 & & & 20 & 80 & 0 \\
\hline \multirow[t]{2}{*}{100} & 2.07 & 2.04 & 92.3 & 0 & 30 & 70 \\
\hline & 2.01 & & & 20 & 80 & 0 \\
\hline \multirow[t]{3}{*}{150} & 1.08 & 1.44 & 65.1 & 0 & 10 & 90 \\
\hline & 2.16 & & & 0 & 60 & 40 \\
\hline & 1.08 & & & 0 & 0 & 100 \\
\hline \multirow[t]{2}{*}{ Number of cycle } & & H-MX & & \multicolumn{3}{|c|}{ Failure mode (\%) } \\
\hline & Strength (MPa) & Mean value (MPa) & Degradation (\%) & Substrate & Interface & Repair \\
\hline \multirow[t]{2}{*}{0} & 2.40 & 2.14 & 100 & 0 & 100 & 0 \\
\hline & 1.89 & & & 0 & 100 & 0 \\
\hline \multirow[t]{2}{*}{50} & 1.82 & 2.04 & 95.4 & 0 & 90 & 10 \\
\hline & 2.26 & & & 0 & 80 & 20 \\
\hline \multirow[t]{2}{*}{100} & 1.49 & 1.89 & 88.0 & 0 & 100 & 0 \\
\hline & 2.28 & & & 0 & 100 & 0 \\
\hline \multirow[t]{2}{*}{150} & 1.37 & 1.40 & 65.4 & 0 & 40 & 60 \\
\hline & 1.43 & & & 0 & 20 & 80 \\
\hline \multirow[t]{2}{*}{ Number of cycle } & & N-MX & & \multicolumn{3}{|c|}{ Failure mode (\%) } \\
\hline & Strength (MPa) & Mean value (MPa) & Degradation (\%) & Substrate & Interface & Repair \\
\hline \multirow[t]{3}{*}{0} & 2.29 & 2.21 & 100 & 15 & 85 & 0 \\
\hline & 2.15 & & & 0 & 100 & 0 \\
\hline & 2.20 & & & 30 & 70 & 0 \\
\hline \multirow[t]{3}{*}{50} & 1.73 & 2.09 & 94.3 & 5 & 95 & 0 \\
\hline & 2.21 & & & 0 & 100 & 0 \\
\hline & 2.32 & & & 10 & 90 & 0 \\
\hline \multirow[t]{2}{*}{100} & 1.70 & 1.99 & 89.8 & 0 & 40 & 60 \\
\hline & 2.27 & & & 35 & 65 & 0 \\
\hline \multirow[t]{2}{*}{150} & 1.32 & 1.49 & 67.3 & 50 & 10 & 40 \\
\hline & 1.66 & & & 30 & 20 & 50 \\
\hline
\end{tabular}




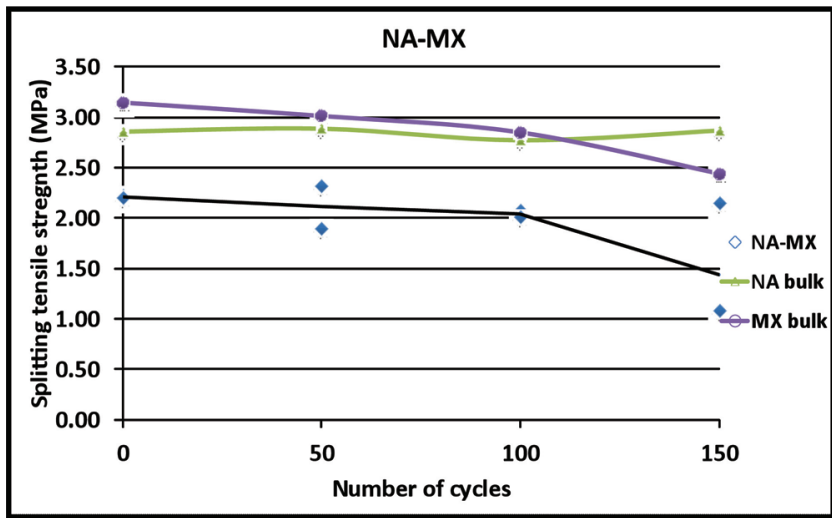

(a)

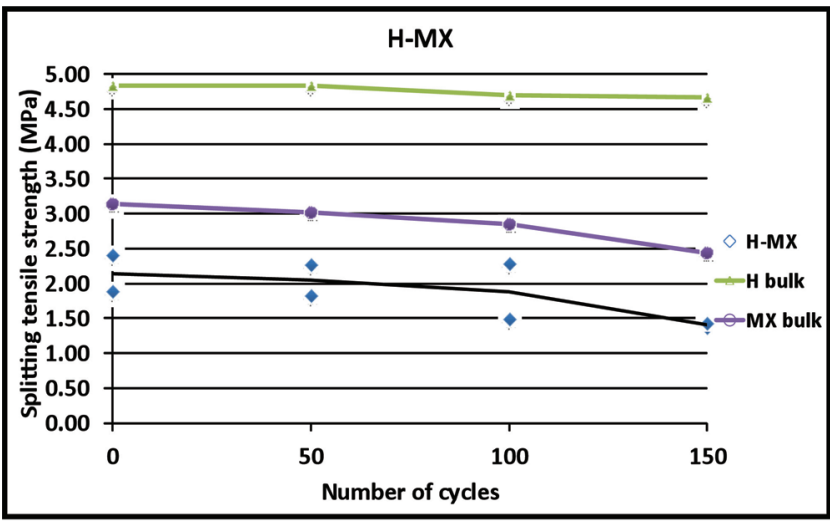

(b)

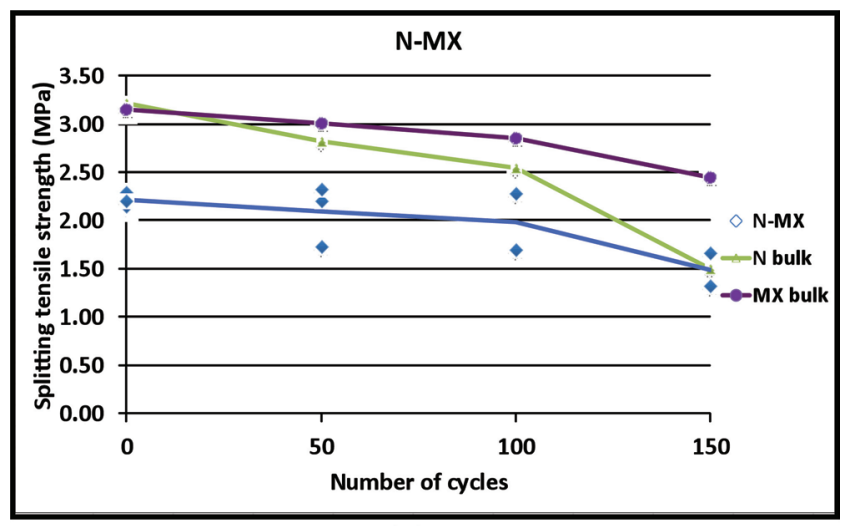

(c)

Figure 8. Splitting tensile strength of composite specimens: (a) NA-MX; (b) H-MX; (c) N-MX.

decreased, as shown in Table 1 and Figure 8. Under 150 freeze-thaw cycles, the splitting tensile strength of NA-MX, $\mathrm{H}-\mathrm{MX}$, and $\mathrm{N}-\mathrm{MX}$ composite specimens decreased to $65.1,65.4$, and $67.3 \%$ of that of 0 cycle, respectively.

For NA-MX composite specimens, without freezethaw cycle, the fracture occurred at the air-entrained normal concrete (NA) side and the adhesive interface, not at the non-air-entrained repairing mortar (MX) side. From RDEM test and splitting tensile test of concrete bulk, it was noted that $\mathrm{MX}$ was damaged under freeze-thaw cycles while NA showed little freezethaw damage. With increasing number of freeze-thaw cycles, increasing percentage of fracture happened at the repairing mortar $(\mathrm{MX})$ side while the percentage of fracture happening at the substrate concrete (NA) and adhesive interface decreased. Under 150 freezethaw cycles, most of the fracture surface happened at the repairing mortar $(\mathrm{MX})$ side while no fracture at the air-entrained normal concrete (NA) side.

For $\mathrm{H}-\mathrm{MX}$ composite specimens, the failure mode with 0 cycle was adhesion failure. With increasing number of freeze-thaw cycles, there was increasing percentage of failure happened at the new repairing mortar (MX) side while decreasing percentage at the adhesive interface. There was no fracture happened at the high strength concrete $(\mathrm{H})$ side. From Figure $8(b)$, it was noted that the splitting tensile strength of high strength concrete $(\mathrm{H})$ was always much higher than that of either non-air-entrained repairing mortar (MX) or the H-MX composite specimens.

For $\mathrm{N}-\mathrm{MX}$ composite specimens, with increasing freeze-thaw cycles, the percentage of interfacial adhesion failure decreased while the percentage of fracture happening at the substrate concrete and repairing material side increased. It was noted that both the substrate concrete and the repairing mortar was non-air-entrained and showed increasing damage under freeze-thaw cycles.

\section{DISCUSSIONS}

Through SEM observation, Xie, Li, and Xiong (2002) found that the hydrates (such as $\mathrm{Ca}(\mathrm{OH})_{2}$, ettringite, and $\mathrm{C}-\mathrm{S}-\mathrm{H}$ ) in the fresh repairing material grew into the cavities and pores at the surface of substrate concrete. They also proposed a model of microstructures of the interfacial zone between substrate and repairing material. The first layer, called the penetration layer, is formed in the cavities and pores at the surface of concrete substrate. They are mainly $\mathrm{C}-\mathrm{S}-\mathrm{H}$ and a little of AFt (ettringite) or $\mathrm{Ca}(\mathrm{OH})_{2}$ (calcium hydrate), with tight structure and no harmful influence on the strength of the interface. The second layer, called the strongly affected layer, is adjacent to the physical boundary between substrate and repairing material and is characterized by high porosity and highly oriented crystal constituents: mainly $\mathrm{Ca}(\mathrm{OH})_{2}$ and needleshaped AFt crystal. This layer is regarded as porous and the weakest layer of the interfacial zone. The third layer, called the weakly affected layer, is located inside the new repairing material and has almost the same microstructures as the new repairing material, therefore is stronger than the second layer: strongly affected layer. When the failure mode is adhesion failure, the fracture happens at the second layer, but 
not at the physical boundary between substrate and repairing material. As the second layer is constituted by hydrates of new repairing material, the strength of adhesive interface thus was greatly influenced by the repairing mortar, which constitutes this layer. The adhesive interface contained more air-entrained voids if the repairing mortar contained air-entraining agent. The adhesive interface containing air-entrained voids did not degrade under freeze-thaw cycles.

For composite specimens repaired with air-entrained mortar (MA), the adhesive interface was constituted by cement hydrates of the fresh repairing mortar, which contain air entraining agent and air-entrained voids. The splitting tensile strength of the adhesive interface, which is the strength of the second layer, did not decrease during freeze-thaw cycles. For NA-MA and H-MA composite specimens, as both substrate concrete and repairing mortar were air-entrained and not damaged during freeze-thaw cycles, the adhesive interface (second layer) was always the weakest part of the composite specimen, resulting in always adhesion failure. For $\mathrm{N}-\mathrm{MA}$ composite specimens, with increasing freeze-thaw cycles, the splitting tensile strength of substrate concrete $(\mathrm{N})$ decreased. Until 100 freeze-thaw cycles, the splitting tensile strength of $\mathrm{N}$ and MA were bigger than the adhesive interface (second layer), causing the adhesion failure at the adhesive interface. While under 150 freeze-thaw cycles, the splitting tensile strength of $\mathrm{N}$ was smaller than that of the adhesive interface (second layer), thus making the failure mode shifted from adhesion failure to cohesion failure at the substrate concrete $(\mathrm{N})$ side rather than the adhesive interface.

For composite specimens repaired with non-airentrained mortar (MX), the adhesive interface was not air-entrained. During freeze-thaw cycles, the adhesive interface was subjected to freeze-thaw damage, and the splitting tensile strength of the adhesive interface decreased. The splitting tensile strength of the composite specimens decreased to 65.1, 65.4, and $67.3 \%$ of that of 0 cycle for NA-MX, H-MX, and N-MX composite specimens, respectively.

By comparing composite specimens repaired with ordinary Portland cement mortar containing air entraining agent or not (MA and MX), it was concluded that the air entraining agent or the air-entrained void in the repairing mortar made the second layer of the adhesive interface air-entrained, having a big effect on the splitting tensile strength of the adhesive interface and failure mode of the composite specimen.

While comparing the three kinds of substrate concrete, the air entraining agent in the substrate concrete $(N, N A$, and $\mathrm{H}$ ) did not show obvious influence on the splitting tensile strength of the adhesive interface. The watercement ratio and air entraining agent in the substrate concrete affected the splitting tensile strength and the freeze-thaw damage of substrate concrete. When the composites showed adhesive failure, difference in substrate concrete had little effect, like in NA and $\mathrm{H}$ based composites. While if the fracture occurred at the substrate concrete, parameters influencing the substrate concrete made a difference such as N-MA composites.

Considering the above-mentioned discussion, the composite specimen is categorized to be three parts: substrate concrete, adhesive interface, and repairing mortar. The fracture occurred at the weakest part of the composite specimen. The failure mode of the composite system is determined by the weakest part under freeze-thaw cycles.

\section{CONCLUSIONS}

Based on the experimental results on tensile bond property of interface between repairing mortars and substrate concretes under freeze thaw cycles in this study, the following conclusions can be drawn:

(1) The splitting tensile strength of adhesive interface did not decrease obviously with up to 150 freezethaw cycles for substrate concrete repaired with air-entrained mortar (MA), while that of adhesive interface decreased for substrate concrete repaired with non-air-entrained mortar (MX).

(2) The air entraining agent of repairing mortar greatly affected the degradation of adhesive interface, especially the second layer (or the weakest layer) of the adhesive interface under freeze-thaw cycles.

(3) The water-cement ratio and air entraining agent of substrate concrete affect insignificantly the adhesive interface under freeze-thaw cycles.

(4) The water-cement ratio and air entraining agent of substrate concrete affected the tensile strength and freeze-thaw resistance of substrate concrete, thus affecting the failure mode and splitting tensile strength of composite specimens when the splitting tensile strength of substrate concrete becomes less than the adhesive tensile strength.

\section{ACKNOWLEDGMENTS}

The authors are grateful to "The Research and Development Grant of Japan Institute of Construction Engineering (JICE)" and the "Express Highway Research Foundation of Japan" for funding this study. The first author is also appreciative of the "Ministry of Education Culture, Sports, Science and Technology Japan (MEXT)" for the scholarship grant. 


\section{REFERENCES}

ASTM C666-03. (2008). Standard test method for resistance of concrete to rapid freezing and thawing. Philadelphia, PA: Author.

ASTM E1876-09. (2009). Standard test method for dynamic young's modulus, shear modulus, and Poisson's ratio by impulse excitation of vibration. Philadelphia, PA: Author.

Austin, S., Robins, P., \& Pan, Y. (1995). Tensile bond testing of concrete repairs. Materials and Structures, 28, 249-259.

Austin, S., Robins, P., \& Pan, Y. (1999). Shear bond testing of concrete repairs. Cement and Concrete Research, 29, 1067-1076.

Emmons, P., \& Vaysburd, A. (1993). Compatibility considerations for durable concrete repairs. Transportation Research Record, 1382, 13-19.

Emmons, P., \& Vaysburd, A. (1994). Factors affecting the durability of concrete repair: The contractor's viewpoint. Construction and Building Materials, 8, 5-16.

Geissert, D. G. (1999). Splitting prism test method to evaluate concrete-to-concrete bond strength. $\mathrm{ACl}$ Materials Journal, 96, 359-366.
Xie, H.-C., Li, G.-Y., \& Xiong, G.-J. (2002). Microstructure model of the interfacial zone between fresh and old concrete. Journal of Wuhan University of Technology-Material Science Edition, 17, 64-68.

Li, G., Xie, H., \& Xiong, G. (2001). Transition zone studies of new-to-old concrete with different binders. Cement and Concrete Composites, 23, 381-387.

Li, G. Y., Wang, P. M., \& Zhao, X. (2007). Pressuresensitive properties and microstructure of carbon nanotube reinforced cement composites. Cement and Concrete Composites, 29, 377-382.

Li, S., Geissert, D. G., Frantz, G. C., \& Stephens, J. E. (1999). Freeze-thaw bond durability of rapidsetting concrete repair materials. ACI Materials Journal, 96.

Morgan, D. (1996). Compatibility of concrete repair materials and systems. Construction and Building Materials, 10, 57-67.

Nilsson, S. (1961). The tensile strength of concrete determined by splitting tests on cubes. RILEM Bulletin, 11, 63-67. 